\title{
Predictors of treatment failure among patients with gunshot wounds and post- traumatic stress disorder
}

\author{
Iurii Leonidovych Kuchyn and Vasyl' Romanovych Horoshko*
}

\begin{abstract}
Background: The $82.1 \%$ treatment failure of post-traumatic stress disorder (PTSD), associated with gunshot wounds, is related to high incidence of chronic pain syndrome as well as resistance to the PTSD treatment. Defining treatment failure predictors among the PTSD patients with gunshot extremity wounds and the following therapy would improve treatment outcomes.

Methods: A total of 218 patients completed the study. The Mississippi Scale for Combat-Related PTSD (M-PTSD) was used for assessment of the treatment outcome rate. The risk relation between treatment failure and factors was assessed by a univariate or multivariate logistic regression method, with the model accuracy measured by the AUC Area under the ROC curve. The odds ratio (OR) was considered for the qualitative factor assessment.

Results: The predictors of the PTSD treatment failure among the patients with gunshot wounds to the extremities are: 1) anesthesia type: the risk of failure is higher with the general anesthesia compared to the regional $(p=0.002)$, $\mathrm{OR}=0.30(95 \% \mathrm{Cl} 0.13-0.69)$ and the regional one with sedation $(p=0.004), \mathrm{OR}=0.30$ (95\% Cl 0,14-0.65); 2 ) severe postoperative pain: the risk of treatment failure rises with increased pain intensity assessed by the visual analogue scale $(p=0.02), \mathrm{OR}=3.2(95 \% \mathrm{Cl} 1.2-8.3)$.
\end{abstract}

Conclusions: The analysis showed that administration of general anesthesia compared to the regional one (regardless of the sedation) and high postoperative pain intensity are associated with higher risk of the PTSD treatment failure among patients with gunshot wounds to the extremities. The preference of regional anesthesia and postoperative pain control may potentially improve the treatment outcomes.

Trial registration: ClinicalTrials.gov: Retrospectively registered on December 30, 2020, NCT04689022.

\section{Background}

War is a strong psycho-social factor affecting all society layers [11], and, first of all, military combatants [9, 12]. The crisis, which they have experienced, predisposes for the PTSD development $[1,4,7]$. According to the WHO, $16.2 \%$ of the world population suffer from the war consequences, and the relatives of $12.5 \%$ were wounded in

*Correspondence: dr.horoshko@ukr.net

National Medical University named after O.O.Bogomolets, Taras

Shevchenko Boulevard, 13, Kyiv 01601, Ukraine action [3]. The PTSD directly causes mental disadaptation of $80 \%$ of the wounded [6], later leading to the selfdestructing behavior, alcohol and drug abuse as well as the other consequences $[2,8,10]$. A wide range of psychotherapy methods for the PTSD therapy has been described, though their effectiveness is questionable $[5,14,15]$. Traumas and somatic disorders of the PTSD patients accumulate their negative effect [16].

Gunshot wounds make up 54-70\% of all combat injuries. According to the Armed Forces of Ukraine Medical Command, the gunshot wounds are represented as follows: $64 \%$ of extremity injuries are represented with original author(s) and the source, provide a link to the Creative Commons licence, and indicate if changes were made. The images or other third party material in this article are included in the article's Creative Commons licence, unless indicated otherwise in a credit line to the material. If material is not included in the article's Creative Commons licence and your intended use is not permitted by statutory regulation or exceeds the permitted use, you will need to obtain permission directly from the copyright holder. To view a copy of this licence, visit http://creativecommons.org/licenses/by/4.0/. The Creative Commons Public Domain Dedication waiver (http://creativeco mmons.org/publicdomain/zero/1.0/) applies to the data made available in this article, unless otherwise stated in a credit line to the data. 
$35.7 \%$ of the upper and $64.3 \%$ of the lower ones. Among them, $74.8 \%$ are the soft tissue injuries, $25.2 \%$ - gunshot fractures. The bone defects are noted in $11.6 \%$ of the patients, and $35-40 \%$ of the patients need subsequent reconstructive interventions.

Regardless of the PTSD treatment progress, psychotherapy and prevention of mental disorders within the psycho-social rehabilitation of the wounded patients haven't been studied properly $[13,16]$.

The subjective feelings and emotional experience of the patients, caused by a combat wound always lead to the PTSD development. So, regarding the PTSD diagnosis, such patients require certain anesthesia. As $82.1 \%$ of all PTSD cases haven't been characterized by the positive treatment outcomes, the study may be significant for the treatment of these patients.

\section{Methods}

The anesthesia used during operations on extremities is the general or regional one. In the study a part of patients who received regional anesthesia were sedated as well, which could also affect the study results. According to anesthesia provision, the patients were divided into 3 groups. Group I received general anesthesia $(n=53)$, the sedation with constant rate infusion of $1 \%$ propofol, $1-4 \mathrm{mg} / \mathrm{kg} / \mathrm{h}$, guided by Bispectral analysis $(60-70-$ for regional anesthesia and 40-60 - for the general one). $0.005 \%$ fentanyl analgesia was injected, $3-10 \mathrm{mkg} / \mathrm{kg}$ or $0.05-0.2 \mathrm{mkg} / \mathrm{kg} / \mathrm{min}$ during induction; and $2-10 \mathrm{mkg} /$ $\mathrm{kg} / \mathrm{h}$ for maintaining analgesia, by periodic bolus injection $25-100 \mathrm{mkg}$ or by permanent infusion. Group II received regional anesthesia: peripheral block was performed $(n=73)$. Group III received regional anesthesia with sedation $(n=92)$. The regional anesthesia was guided by ultrasound (apparatus Mindray DP-30 with linear array probe $5-10 \mathrm{MHz}$ ). A needle was inserted near the nerve roots and $20-30 \mathrm{ml}$ of $0.5 \%$ bupivacaine was injected. The postoperative pain management of the I group patients was provided according to the local clinical protocol: paracetamol $+/-$ non-steroid anti-inflammatory drugs $+/$-opioids; of the II and III group patients -repeated peripheral block or prolonged regional anesthesia with $0.25 \%$ bupivacaine solution.

The PTSD progress and treatment effectiveness were estimated using the Mississippi Scale for Combat-Related PTSD (M-PTSD), anesthesia risks - the American Society of Anesthesiologists (ASA) classification, pain intensity - the visual analogue scale (VAS), neuropathic pain component - the Douleur Neuropathique 4 questions (DN4).

Trial registration - ClinicalTrials.gov: Retrospectively registered on December 30, 2020, NCT04689022.

\section{Data collection and extraction}

The study was held within the bioethics expertise protocol No.125 of October 21, 2019 issued by the Commission on Biotic Expertise and Research Ethics of O.Bogomolets National medical university, Ministry of Health of Ukraine. All study data are recorded in the patients' reports, stored in the archive of the National military medical clinical center "Main military clinical hospital”, 18 Hospital street, Kyiv, Ukraine. Statistical analysis was performed using the EZR v.1.35 software ( $\mathrm{R}$ statistical software version 3.4.3, R Foundation for Statistical Computing, Vienna, Austria).

\section{Statistical analysis}

Statistical analysis was performed using the EZR v.1.35 software ( $\mathrm{R}$ statistical software version 3.4.3, $\mathrm{R}$ Foundation for Statistical Computing, Vienna, Austria).

A univariate or multivariate logistic regression method was used to assess the risk relation between treatment failure and factors. The model accuracy was measured by the AUC - Area under the ROC curve, with the 95\% confidence interval (CI). The Odds Ratio (OR) and its 95\% CI were calculated for the qualitative factor effect assessment (the significance level of $5 \%$ ), $p=0.05$.

\section{Results}

The study is based on the authors' clinical experience of treatment of 218 combatants with gunshot wounds to the extremities, accompanied with the PTSD, during 2014-2019, the patients operated under anesthesia.

The treatment outcome rate was assessed by the Mississippi Scale for Combat-Related PTSD (M-PTSD). A positive outcome rate is represented with the patient post-discharge positive coping, which corresponds to 94-58 points, observed in 39 patients (17.9\%). A treatment failure is regarded as the absent PTSD treatment effect after discharge, which corresponds to 148-113 points, observed in 5 patients $(2.3 \%)$ and psychic disorders, which correspond to $112-95$ points, observed in 174 patients $(79,8 \%)$. The results evidence about the $82.1 \%$ post-discharge treatment failure.

The variables of the PTSD patients with the extremity gunshot wounds, operated under anesthesia, were equal by Kruskal-Wallis test (see Table 1 ).

The following 17 characteristics of the PTSD treatment failure were assessed: anesthesia type, patient age, height and weight; BMI; ASA score; operation duration; anesthesia duration; systolic and diastolic arterial pressure; heart rate; pre- and post-operative pain intensity measured by the VAS scale; pre-operative neuropathic pain by the DN4, pre- and post-operative M-PTSD, 
Table 1 Variables of patients with the PTSD, associated with the extremity gunshot wounds $\bar{X} \pm S D$

\begin{tabular}{|c|c|c|c|c|}
\hline \multirow[t]{2}{*}{ Variable } & \multicolumn{3}{|l|}{ Anesthesia type } & \multirow[t]{2}{*}{$p$} \\
\hline & $\begin{array}{l}\text { General anesthesia } \\
(n=53)\end{array}$ & $\begin{array}{l}\text { Regional anesthesia } \\
(n=73)\end{array}$ & $\begin{array}{l}\text { Regional anesthesia and } \\
\text { sedation } \\
(n=92)\end{array}$ & \\
\hline Age (years) & $31.7 \pm 8.8$ & $32.6 \pm 10.1$ & $33.3 \pm 8.5$ & 0.424 \\
\hline Height (cm) & $178.2 \pm 7.3$ & $178 \pm 5.6$ & $179.9 \pm 4.9$ & 0.101 \\
\hline Weight (kg) & $79.9 \pm 10.4$ & $80.7 \pm 8.4$ & $80.7 \pm 6.3$ & 0.414 \\
\hline Anesthesia duration (min) & $140.7 \pm 80.5$ & $147.7 \pm 75.4$ & $145.4 \pm 66.1$ & 0.762 \\
\hline Operation duration (min) & $121.4 \pm 74.5$ & $132.7 \pm 77.2$ & $130.4 \pm 68.5$ & 0.601 \\
\hline
\end{tabular}

Table 2 Coefficients of univariate logistic regressions of the treatment failure risks prognosis

\begin{tabular}{|c|c|c|c|c|}
\hline Factor variable & & Coefficient, $b \pm m$ & $P$ & $\begin{array}{l}\text { OR } \\
(95 \% \mathrm{Cl})\end{array}$ \\
\hline \multirow[t]{3}{*}{ Anesthesia types } & General anesthesia & Reference & & \\
\hline & Regional anesthesia & $-1.20 \pm 0.42$ & 0.004 & $0.30(0.13-0.69)$ \\
\hline & $\begin{array}{l}\text { Regional anesthesia and seda- } \\
\text { tion }\end{array}$ & $-1.21 \pm 0.40$ & 0.002 & $0.30(0.14-0.65)$ \\
\hline Age & & $0.016 \pm 0.018$ & 0.360 & - \\
\hline Height & & $-0.009 \pm 0.005$ & 0.076 & - \\
\hline Weight & & $-0.027 \pm 0.021$ & 0.203 & - \\
\hline IMT & & $0.0005 \pm 0.0004$ & 0.160 & - \\
\hline ASA & & $0.67 \pm 0.36$ & 0.063 & - \\
\hline Anesthesia duration & & $0.0034 \pm 0.0021$ & 0.098 & - \\
\hline Surgery duration & & $0.0032 \pm 0.0021$ & 0.125 & - \\
\hline Sys AT & & $-0.010 \pm 0.019$ & 0.589 & - \\
\hline Dia AT & & $0.003 \pm 0.023$ & 0.907 & - \\
\hline Heart rate & & $0.016 \pm 0.018$ & 0.369 & - \\
\hline Pre-operative VAS & & $-0.03 \pm 0.25$ & 0.889 & - \\
\hline Pre-operativeDN4 & & $0.19 \pm 0.25$ & 0.445 & - \\
\hline Pre-operative M-PTSD & & $-0.03 \pm 0.26$ & 0.919 & - \\
\hline Post-operative VAS & & $0.30 \pm 0.22$ & 0.177 & - \\
\hline Post-operative m-PTSD & & $-0.013 \pm 0.028$ & 0.634 & - \\
\hline Pre-operative blood glucose level & & $-0.12 \pm 0.21$ & 0.573 & - \\
\hline Post-operative blood glucose level & & $-0.29 \pm 0.29$ & 0.321 & - \\
\hline
\end{tabular}

pre-and post-operative blood glucose level. The results are offered in Table 2 .

The dependent variable was represented with the M-PTSD data. If the post-treatment M-PTSD exceeded 75 points, the treatment was considered to fail (dependent variable $\mathrm{Y}=1$, with 48 combatants altogether). If the post-treatment M-PTSD didn't exceed 75 points, the treatment was considered productive (dependent variable $\mathrm{Y}=0$, with 170 combatants altogether). The authors used a univariate and multivariate logistic regression methods.
The univariate analysis revealed relationship $(p<0.05)$ with the anesthesia type. As for the combatants who were given general anesthesia, the risk is higher, compared to the regional anesthesia $(p=0.002), \mathrm{OR}=0.30$ (95\% CI 0.13-0.69) and regional anesthesia with sedation ( $p=0.004), \mathrm{OR}=0.30$ (95\% CI 0.14-0.65).

The multivariate logistic regression was chosen for the significant variables selection (by stepwise method, with the reporting threshold of entry $p<0.2$ and exit $p>0.3)$. Six factors have been selected: anesthesia type, height, BMI, ASA risk, heart rate, and the pre-operative 


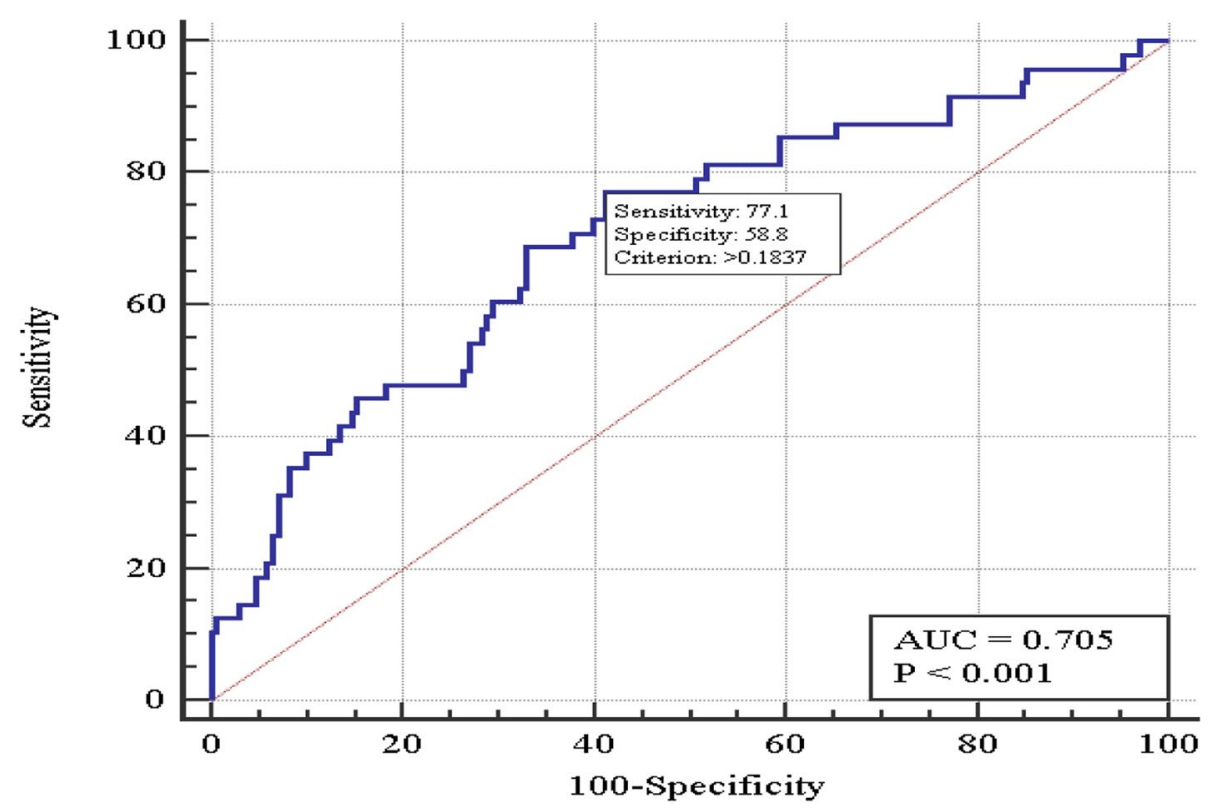

Fig. 1 The M-PTSD treatment failure model curve (the PTSD patients with gunshot wounds to extremities)

M-PTSD. As a result, multi-variate valid logistic regression of treatment failure prognosis with 6 variables was built $\left(\chi^{2}=26,7\right.$ with $\left.p=0.002\right)$. Figure 1 shows the operation characteristic curve. The Area under the operation characteristic curve, AUC $=0.71$ (95\% CI 0.64-0.77) evidences about the relationship between the factors and treatment failure.

Table 3 shows the critical threshold as well as the model sensitivity and specificity within the threshold.

As the table shows, the probability (standardized by 5 risk factors) of the M-PTSD treatment failure for the military combatants operated under general anesthesia is higher $(p=0.002), \mathrm{OR}=0.23$ (95\% CI 0.08 0.59 ), compared to regional anesthesia and regional anesthesia with sedation $(p=0.003), \mathrm{OR}=0.23(95 \% \mathrm{CI}$ 0.09-0.61).

The M-PTSD treatment outcomes after general anesthesia are significantly worse, so, it was decided to analyze treatment failure risk in the group in which regional and regional anesthesia with sedation were used (165 patients). The same risk factors were analyzed. Two factors were emphasized: the postoperative VAS-assessed pain intensity and age. A bi-variate valid logistic regression model was used $\left(x^{2}=9.5, p=0.009\right)$. Figure 2 shows the treatment failure bi-variate model characteristics curve. The area under the operating characteristics curve $\mathrm{AUC}=0.70$ (95\% CI 0.62-0.77), which confirms relationship between the treatment failure and the factors.

Table 3 Coefficients of the multi-variate six-factor logistic regression model of the PTSD treatment failure prognosis (in combatants with the gunshot wounds to extremities)

\begin{tabular}{|c|c|c|c|c|}
\hline Variable & & Model coefficient, $\mathbf{b} \pm \mathbf{m}$ & Significance level & $\begin{array}{l}\text { OR } \\
(95 \% \mathrm{Cl})\end{array}$ \\
\hline \multirow[t]{3}{*}{ Anesthesia types } & General anesthesia & Reference & & \\
\hline & Regional anesthesia & $-1.50 \pm 0.49$ & 0.002 & $0.23(0.08-0.59)$ \\
\hline & $\begin{array}{l}\text { Regional anesthesia and } \\
\text { sedation }\end{array}$ & $-1.46 \pm 0.49$ & 0.003 & $0.23(0.09-0.61)$ \\
\hline Height & & $-0.056 \pm 0.030$ & 0.059 & - \\
\hline BMI & & $0.0036 \pm 0.0020$ & 0.083 & - \\
\hline ASA & & $0.54 \pm 0.38$ & 0.155 & - \\
\hline $\mathrm{HR}$ & & $0.031 \pm 0.020$ & 0.120 & - \\
\hline Pre-operative M-PTSD & & $0.057 \pm 0.35$ & 0.100 & - \\
\hline
\end{tabular}




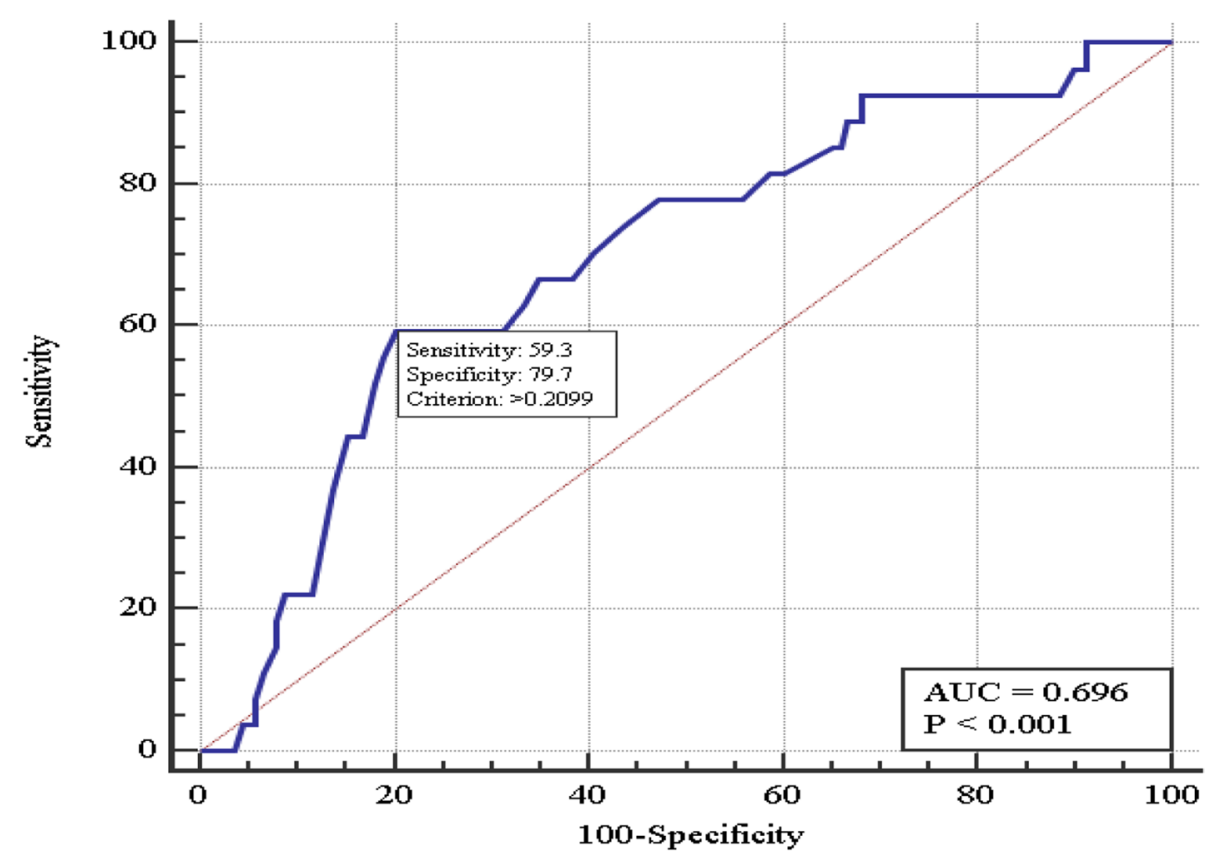

Fig. 2 The PTSD treatment failure prognosis model curve (the patients with gunshot wounds to extremities, operated under regional anesthesia, with or without sedation)

Table 4 Coefficients of the bi-variate logistic regression model of treatment failure prognosis for the PTSD combatants with the gunshot wounds to extremities, operated under regional) anesthesia (with or without sedation)

\begin{tabular}{llll}
\hline Variable & $\begin{array}{l}\text { Model coefficient, } \\
\mathbf{b} \pm \mathbf{m}\end{array}$ & $\begin{array}{l}\text { Significance } \\
\text { level }\end{array}$ & $\begin{array}{l}\text { OR } \\
\mathbf{( 9 5 \% ~ C I )}\end{array}$ \\
\hline Age & $0.044 \pm 0.022$ & 0.05 & $1.04(1.00-1.09)$ \\
Post-operative VAS & $1.16 \pm 0.49$ & 0.02 & $3.2(1.2-8.3)$ \\
\hline
\end{tabular}

Table 4 shows the critical threshold, sensitivity and specificity of the model with the chosen threshold as well as the multi-variate analysis of the treatment failure prognosis.

The probability of the PTSD treatment failure for the wounded combatants operated under regional anesthesia (with or without sedation) increases $(p=0.05)$ with the VAS-assessed post-operative pain intensity increase $(p=0.02), \mathrm{OR}=3.2(95 \% \mathrm{CI} 1.2-8.3)$ for each point (standardized by age) as well as with the age, OR $=1.04$ (95\% CI 1.00-1.09) for each year (standardized by the post-operative VAS-assessed pain intensity).

\section{Discussion}

It has been noted that the PTSD in military combatants results from their direct participation in military actions $[1,4,7]$. The study revealed that if a military combatant was wounded during the action operation, his emotional and subjective feelings will $100 \%$ lead to the PTSD. Other scientists $[2,8,10]$ state about the PTSD remote treatment failure in $80 \%$ of the military combatants. The study evidences about $82.1 \%$ of the PTSD m-related wounds treatment failure, which was essential for the subsequent studies. Some authors $[5,14,15]$ state about treatment effectiveness of psychopharmacological drugs and psychotherapy, which is rather questionable. Traumas and somatic diseases in the PTSD patients are known to accumulate their negative effects [16]. So, definition of the PTSD treatment failure predictors may improve treatment outcomes.

The following 17 characteristics of the PTSD treatment failure were assessed for defining the PTSD treatment failure predictors: anesthesia type, patient age, height and weight; BMI; ASA score; operation duration; anesthesia duration; systolic and diastolic arterial pressure; heart rate; pre- and post-operative pain intensity by the VAS scale; pre-operative neuropathic pain by theDN4, pre- and post-operative M-PTSD, pre-and post-operative blood glucose level. The study revealed that the probability of the PTSD treatment failure is higher for the military combatants operated under general anesthesia (standardized by 5 risk factors) compared to regional anesthesia $(p=0.002)$ OR $=0.23$ (95\% CI 0.08-0.59) and regional anesthesia with sedation $(p=0.003), \mathrm{OR}=0.23$ (95\% CI 0.09-0.61). The probability of the PTSD treatment failure for the wounded combatants operated under 
regional anesthesia (with or without sedation) increases $(p=0.05)$ with the VAS - assessed post-operative pain intensity increase $(p=0.02), \mathrm{OR}=3.2(95 \%$ CI $1.2-8.3)$ for each point (standardized by age).

So, the use of general anesthesia compared to regional (regardless of sedation) and high postoperative pain intensity are associated with a higher risk of the PTSD treatment failure in patients with the gunshot wounds to extremities. The study evidences that the choice of regional anesthesia and post-operative pain control may significantly improve treatment outcomes in such patients.

\section{Conclusions}

The analysis of 218 PTSD patients with gunshot wounds, operated under anesthesia, showed that the use of general anesthesia compared to regional (regardless of sedation) and high postoperative pain intensity are associated with a higher risk of the PTSD treatment failure in patients with the gunshot wounds to extremities. The choice of regional anesthesia and post-operative pain control may significantly improve treatment outcomes in such patients.

\section{Supplementary Information}

The online version contains supplementary material available at https://doi. org/10.1186/s12871-021-01482-8.

\section{Additional file 1.}

\section{Acknowledgements}

Not applicable.

\section{Authors' contributions}

Kuchyn lu.L. - study concept and design; Horoshko V.R. - collection and processing of the data, analysis, composing the paper. The author(s) read and approved the final manuscript.

\section{Funding}

None.

\section{Availability of data and materials}

The datasets used and analysed during the current study are available from the corresponding author on reasonable request.

\section{Declarations}

\section{Ethics approval and consent to participate}

The study was held within the bioethics expertise protocol No.125 of October 21, 2019 issued by the Commission on Biotic Expertise and Research Ethics of O.Bogomolets National medical university, Ministry of Health of Ukraine. I confirm that all methods have been performed in accordance with the relevant guidelines and standards by including a statement in the Methods section.

All study participants provided informed consent to participate in accordance with the protocol on bioethical examination No. 125 of October 21, 2019, issued by the Commission on Biotic Expertise and Research Ethics of the Bogomolets National Medical University, Ministry of Health of Ukraine.

\section{Consent for publication}

All patients gave informed voluntary consent in accordance with the policy of the study, as well as the use of her personal, clinical data, along with any identifying images that may be used in the publications of this study.

\section{Competing interests}

The authors declare that they have no competing interests.

Received: 30 December 2020 Accepted: 8 October 2021

Published online: 30 October 2021

\section{References}

1. Agaibi CE, Wilson JP. Trauma, PTSD, and resilience: a review of the literature. Trauma Violence Abuse. 2005;6(3):195-216. https://doi.org/10.1177/15248 38005277438.

2. Back SE, Brady KT, Sonne SC, Verduin ML. Symptom improvement in COoccurring PTSD and alcohol dependence. J Nerv Ment Dis. 2006;194(9):6906. https://doi.org/10.1097/01.nmd.0000235794.12794.8a Erratum in: J Nerv Ment Dis. 2006; 194(11):825.

3. Badiuk ML, Shevchuk OS. The combat stress reaction as a scientific problem of the world, and its social and medical consequences. Clin Exp Pathol. 2016:4:10-4.

4. Barton S, Boals A, Knowles L. Thinking about trauma: the unique contributions of event centrality and posttraumatic cognitions in predicting PTSD and posttraumatic growth. J Trauma Stress. 2013;26(6):718-26. https://doi. org/10.1002/jts.21863.

5. Beck AT, Emery G, Greenberg RL. Anxiety disorders and phobias: a cognitive approach. New York: Basic; 2015. p. 86.

6. Dalenberg C, Carlson EB. Dissociation in posttraumatic stress disorder part 2: how theoretical models fit the empirical evidence and recommendations for modifying the diagnostic criteria for PTSD. Psychol Trauma Theory Res Pract Policy. 2012;4(6):551-9. https://doi.org/10.1037/a0027900.

7. Gillihan SJ, Cahill SP, Foa EB. Psychological theories of PTSD. New York: Guilford Press; 2014. p. 166-85.

8. Haller M, Chassin L. The influence of PTSD symptoms on alcohol and drug problems: internalizing and externalizing pathways. Psychol Trauma Theory Res Pract Policy. 2013;5(5):484-93. https://doi.org/10.1037/a0029335.

9. Hoge CW, Auchterlonie JL, Milliken CS. Mental health problems, use of mental health services, and attrition from military service after returning from deployment to Iraq or Afghanistan. JAMA. 2006;295(9):1023-32. https://doi. org/10.1001/jama.295.9.1023.

10. Kolyadko SP, Denisenko MM, Kalenskaya GY, Yavdak IO. Clinical and psychopathological features of patients with neurotic disorders with comorbid addictive disorders. Ukrainian Bull Psychoneurol. 2016:24(1):64-8.

11. Matyash MM, Khudenko LI. Social stress disorders in the structure of the Ukrainian syndrome. Ukrainian J. 2016;3:113.

12. Minko Ol, Linskyyi IV, Baranenko OV. Alcoholic behavior and its consequences in the ATO veterans and civilians affected by the "hybrid war". Ukrainian Bull Psychoneurol. 2017;25:190.

13. Marcia JE. Life transitions and stress in the context of psychosocial development. In: Miller TW, editor. Handbook of stressful transitions across the lifespan. Berlin: Springer Science+Business Media; 2010. p. 19-34. https:// doi.org/10.1007/978-1-4419-0748-6 2.

14. Rothbaum BO, Schwartz AC. Exposure therapy for posttraumatic stress disorder. Am J Psychother. 2002;56(1):59-75. https://doi.org/10.1176/appi. psychotherapy.2002.56.1.59.

15. Teng EJ. Efficacy of posttraumatic stress disorder treatment for comorbid panic disorder: a critical review and future directions for treatment research. Clin Psychol Sci Pract. 2016:68-84. https://doi.org/10.1111/cpsp.12039.

16. Voloshyn PV, Maruta NO. The main directions of scientific research in neurology, psychiatry and narcology of Ukraine. Ukrainian Bull Psychoneurol. 2017:25(1):10-8.

\section{Publisher's Note}

Springer Nature remains neutral with regard to jurisdictional claims in published maps and institutional affiliations. 